\author{
Military Technical College \\ Kobry El-Kobbah, \\ Cairo, Egypt
}

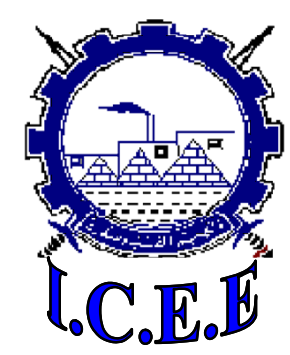

$5^{\text {th }}$ International Conference on

\section{Chemical \& Environmental} Engineering 25 - 27 May, 2010.

NBC-2

NBC Protection

\title{
NEW TRENDS IN PROTECTION AGAINST CHEMICAL WARFARE AGENTS
}

\section{ABSTRACT}

\author{
Ahmed F. Abdel-Aziz*
}

One of the greatest threats in modern world is the possibility of use of chemical weapons by regular forces or by terrorist groups. Among these weapons, the so -called neurotoxic agents, commonly known as "Nerve Agents", constitute the greate st concern, due to their highly deleterious effects on humans. The potentiality of attack employing these agents gives a strong reason for continuous research on the development of more effective protection, detection and antidotes. In this paper the main aspects concerning the development of individual and collective protections against these agents.

\footnotetext{
${ }^{*}$ Egyptian Armed Forces
} 